\title{
Diagnosis of ECG Signal and Prediction of Critical Diseases for Cardiac Patients using MATLAB
}

\author{
Anurag Shrivastava ${ }^{1}$, Dr. Vivek Chandra ${ }^{2}$, Dr. G .R Sinha ${ }^{3}$ \\ Assistant Professor /Scientist, BRSM College of Agricultural Engineering \& Technology and Research Station, \\ IGKV, Mungeli, (C.G) India ${ }^{1}$ \\ Professor \& H.O.D, Chatrapati Shivaji Institute of Technology, Durg, (C.G) India ${ }^{2}$ \\ Professor \& Associate Director, Shri Shankaracharya College of Engineering and Technology, Bhilai, (C.G) India ${ }^{3}$
}

\begin{abstract}
In recent decade, ECG signal plays an important role in the prognosis, diagnosis and survival analysis of cardiac diseases. Electrocardiography (ECG) has profound influence on the practice of medicine. The electrocardiogram signal contains important information's that can be exploited in various manners. The ECG signal allows the analysis of anatomic and physiologic aspects of the whole cardiac system. This research paper proposes an algorithm for analysis of ECG signals for detecting various cardiac diseases .Different ECG signals are used to test the proposed method using MATLAB software.
\end{abstract}

Keywords: ECG (Electrocardiogram), MATLAB, Cardiac Patients, Critical Diseases, Diagnosis.

\section{INTRODUCTION}

The electrocardiogram (ECG) is a diagnostic tool that measures and records the cardiac activity of the heart in detail and is used to interpret a wide range of heart problems. The development of the electrocardiograph is a scientific effort aimed to perfecting a device conceived for the elucidation of a physiological phenomenon. The innovation of the digital computer was scientific effort aimed for a time proving man's welfare.

These two are fairly recent innovations of modern technology have been successful in their main initial objectives. During the past few decades the analysis of the ECG signal transformed from the simple visual inspection to completely automated diagnosis systems. The parameters of ECG signal is used for measuring variability's of heart activity. So that it is very much important to extract the parameters of ECG signal without noise.

This step gives a full idea and complete information about the electrophysiology of the heart diseases and the ischemic changes that may occur like the myocardial infarction, conduction defects and arrhythmia.

In order to support clinical decision-making, the ECG signal must be clearly represented and filtered, to remove out all the noises and artifacts from the signal. ECG signal is one of the bio signals which is considered as a nonstationary signal and needs a lot of effort for de-noising. An efficient technique for such non-stationary signal processing is proposed in this paper.

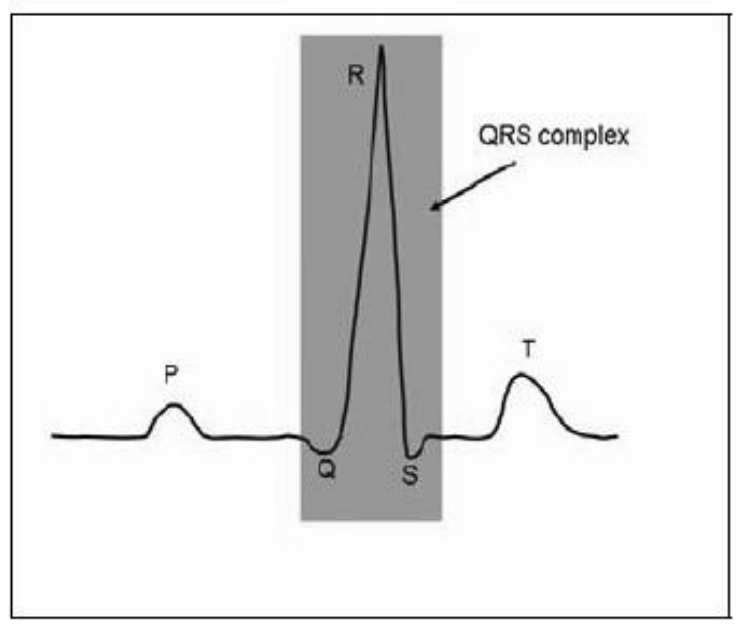

Figure 1: An "ideal" ECG signal from a healthy subject (time duration equivalent to one heartbeat). Key features, including the QRS complex, are identified.

\section{ALGORITHM FOR ECG ANALYSIS}

When developing new algorithms for bio signal analysis, several tools are required to help the developer finding the suitable features of the signal, implementing the algorithm, validating the algorithm's results and optimizing existing algorithms in order to achieve a predefined optimal performance.

Given below is the flow chart of proposed algorithm. 


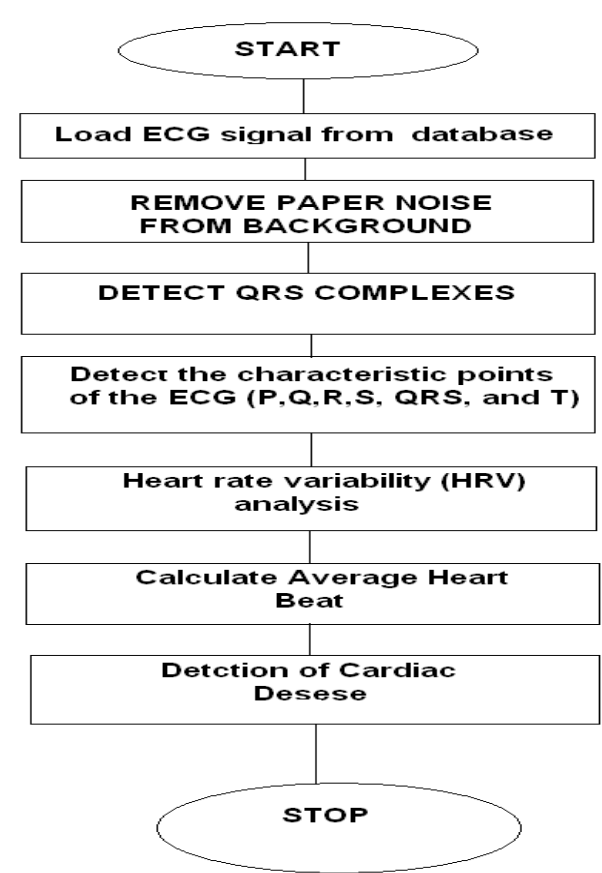

Fig 2: Flow Chart for Proposed Algorithm

GUI for proposed Algorithm and Functionality

GUI has been developed on the basis of above algorithm. In the first step the ECG is taken from database in .jpg format. In the next step it is converted into gray scale and after that paper noise is removed as shown in figure 3.

The second part of GUI contains a Demo standard ECG signal for reference.

In the third part we have to provide information about the $\mathrm{P}$ wave that is $\mathrm{P}$ wave is Upright, downwards or absent.

In the last section as we click on to the "Examine and Show Result", The processing of algorithm starts and result will be displayed.

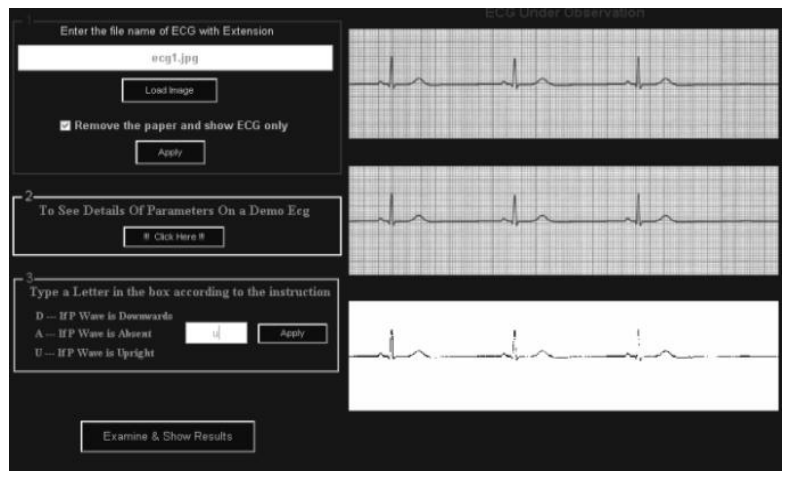

Fig 3: GUI for Proposed Algorithm

\section{RESULT AND CONCLUSION}

The analysis of various ECG samples is shown in below figures and also collective interpretation is drawn in Table1, The analysis of sample in figure 4 shows that the patient will be suffering from Paroxymal Super ventricular Tachycardia. The analyzing parameter is also shown in the respective figures.

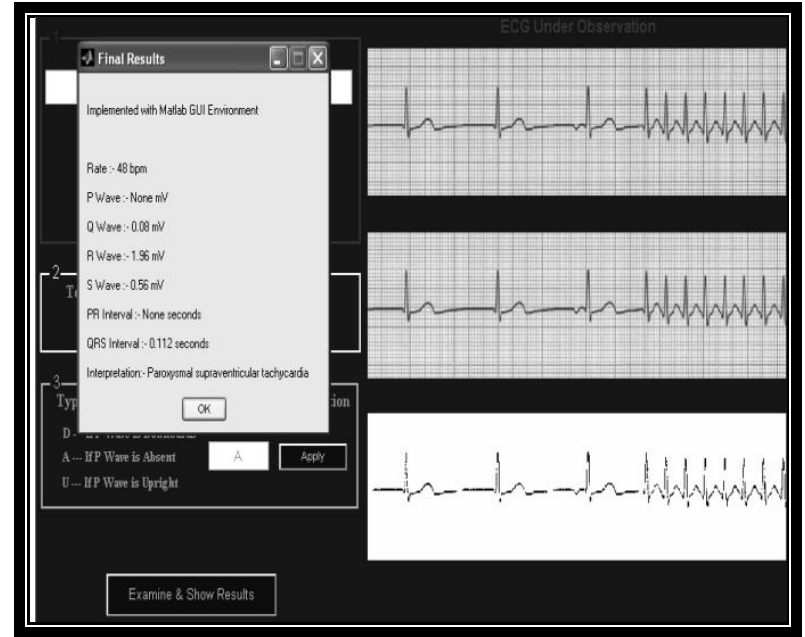

Fig 4: An ECG sample analysis and analysis result

The analysis of sample in Figure 5 shows that the patient will be suffering from Sinus Rhythm with Sinus Arrest. The parameters are tabulated in Table 1

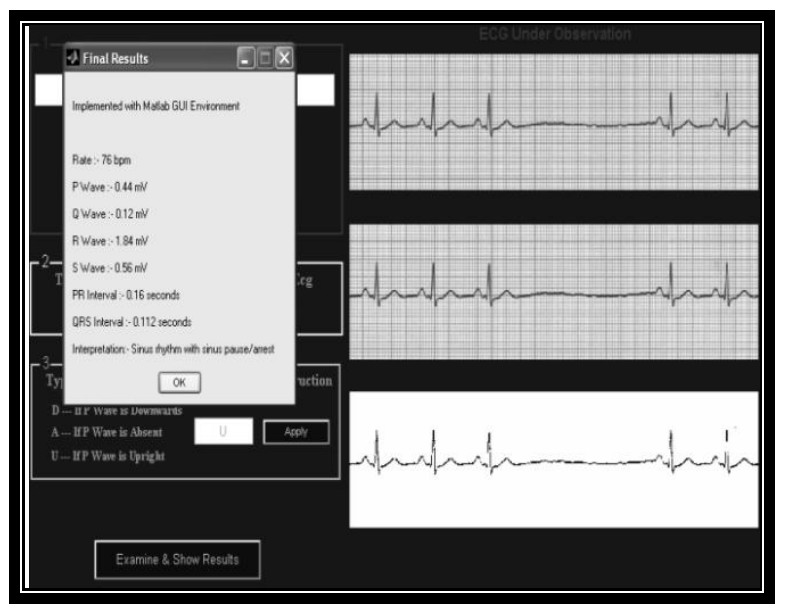

Fig 5: An ECG sample analysis and analysis result

The analysis of sample in Figure 6 shows that the patient will be suffering from Sinus Rhythm with Sinus Arrest.

Table 1: Analysis of Various ECG Samples

\begin{tabular}{|l|l|l|l|l|}
\hline $\begin{array}{l}\text { S. } \\
\text { No }\end{array}$ & $\begin{array}{l}\text { QRS } \\
\text { Interval } \\
(\mathbf{m V})\end{array}$ & $\begin{array}{l}\mathbf{Q} \\
\text { Interval } \\
(\mathbf{m V})\end{array}$ & $\begin{array}{l}\text { Heart } \\
\text { Rate } \\
(\mathbf{B P M})\end{array}$ & Disease \\
\hline 1 & 0.112 & 0.08 & 48 & $\begin{array}{l}\text { Paroxymal } \\
\text { Super } \\
\text { ventricular } \\
\text { Tachycardia }\end{array}$ \\
\hline 2 & 0.112 & 0.012 & 76 & $\begin{array}{l}\text { Sinus } \\
\text { Rhythm with } \\
\text { Sinus Arrest. }\end{array}$ \\
\hline 3 & 0.096 & 0.08 & 58 & $\begin{array}{l}\text { Sinus } \\
\text { Bradycardia } \\
\text { with first } \\
\text { degree AV } \\
\text { block A }\end{array}$ \\
\hline
\end{tabular}


Table 1 gives the collective interpretation of all the sample of the above figures based on the parameters calculated on the basis of the proposed algorithm.

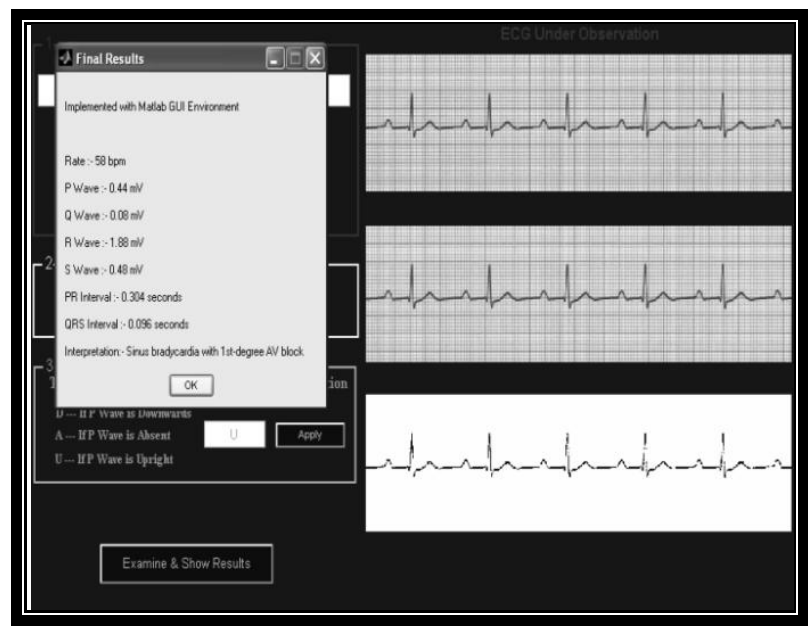

Figure 6: An ECG sample analysis and analysis result

\section{REFERENCES}

[1] Jiao et al., 2012, Modified Log-LMS adaptive filter with low signal distortion for biomedical applications, 34th Annual International Conference of the IEEE EMBS San Diego, California USA :5210-5213.

[2] Kazi et al., 2012, Least Mean Square Algorithm Based Adaptive Filters for Removing Power Line Interference from ECG Signal, IEEE/OSA/IAPR International

[3] Conference on Informatics Electronics \& Vision, Dhaka Bangladesh: 737-74.

[4] Hayn et al."2009, "A Biosignal Analysis System Applied for Developing an Algorithm Predicting Critical Situations of High Risk Cardiac Patients by Hemodynamic Monitoring”, 36th Annual Computers in Cardiology Conference (CinC) Date 13-16 Sept. 2009.

[5] Zentrum, et al."Validation, and Optimisation of High-Quality ECG Processing Algorithms" Institute of Biomedical Engineering University for Health Sciences, Medical Informatics and Technology I A-6060 Hall/Tirol.

[6] "Noise Reduction for Heart Sounds Using a Modified MinimumMean Squared Error Estimator with ECG Gating". Proceedings of the 28th IEEE EMBS Annual International Conference New York City, USA, Aug 30-Sept 3, 2006.

[7] Computer Analysis of the Electrocardiograms from ECG paper RecordingsS . 2001 Proceedings of the 23rd Annual EMBS International Conference, October 25-28, Istanbul, Turkey.

[8] Laguna et al. (1997)." A database for evaluation of algorithms for measurement of QT and other waveform intervals in the ECG." Computers in Cardiology, pages 673-676.

[9] Daskalov et al. (1999). "Automatic detection of the electrocardiogram T-wave end". Med Biol Eng Comput, 37(3): 348-353.

[10] Albrecht et al.: "Efficient measurement of long term ST segment trends". Proc. of the Fifth Annu. Cons, pp. 644449, 1983. 